Viso - Cadernos de estética aplicada Revista eletrônica de estética

ISSN 1981-4062

$N^{\circ} 4$, jan-jun/2008

http://www.revistaviso.com.br/
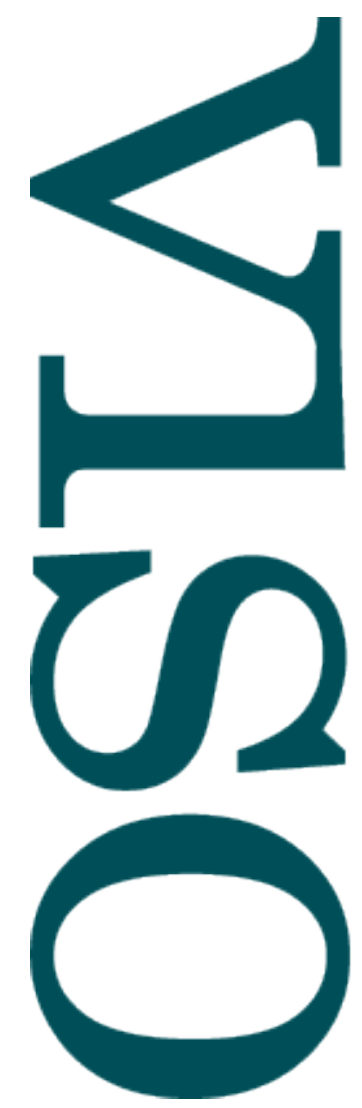

\title{
O cinema brasileiro em perspectiva: a atualidade de Brasil em tempo de cinema de Jean-Claude Bernadet
}

\author{
André L. Bertelli Duarte
}




\section{RESUMO}

O cinema brasileiro em perspectiva: a atualidade de Brasil em tempo de cinema de Jean-Claude Bernadet

Brasil em tempo de cinema é a maior obra de estética cinematográfica do cinema brasileiro. Relançada quarenta anos após a edição original, mantêm-se atual, não somente devido ao rigor crítico de Bernadet sob o ponto de vista artístico, mas, sobretudo, pela pertinência das reflexões acerca dos desdobramentos culturais e políticos na história do cinema nacional.

Palavras-chave: história - estética - Cinema Novo

\section{ABSTRACT}

Brazilian Cinema in Perspective: The Importance of Jean-Claude Bernardet's Brasil em tempo de cinema

Brasil em Tempo de Cinema is one the greatest books on Brazilian cinematographic aesthetics. Republished forty years after its original release, it remains important to contemporary discussions not only because of Bernadet's rigorous critical analysis of movies under a strictly artistical point of view, but, more importantly, because of the his reflexions on cultural and political developments in the history of Brazilian cinema.

Keywords: History - Aesthetics - New Cinema 
BERTELLI, A. L. "O cinema brasileiro em perspectiva: a atualidade de Brasil em tempo de cinema de JeanClaude Bernadet". In: Viso: Cadernos de estética aplicada, v. II, n. 4 (jan-jun/2008), pp. 65-73.

DOI: $10.22409 / 1981-4062 / v 4 i / 94$

Aprovado: 13.02.2008. Publicado: 30.06.2008.

(c) 2008 André Luis Bertelli. Esse documento é distribuído nos termos da licença Creative Commons Atribuição-NãoComercial 4.0 Internacional (CC-BY-NC), que permite, exceto para fins comerciais, copiar e redistribuir o material em qualquer formato ou meio, bem como remixá-lo, transformá-lo ou criar a partir dele, desde que seja dado o devido crédito e indicada a licença sob a qual ele foi originalmente publicado.

Licença: http://creativecommons.org/licenses/by-nc/4.0/deed.pt_BR

Accepted: 13.02.2008. Publicado: 30.06.2008.

(c) 2008 André Luis Bertelli. This document is distributed under the terms of a Creative Commons Attribution-NonCommercial 4.0 International license (CC-BY-NC) which allows, except for commercial purposes, to copy and redistribute the material in any medium or format and to remix, transform, and build upon the material, provided the original work is properly cited and states its license.

License: http://creativecommons.org/licenses/by-nc/4.0/ 
A Companhia das Letras traz um presente para os estudiosos e amantes do cinema brasileiro. Trata-se de Brasil em tempo de cinema: Ensaio sobre o cinema brasileiro de 1958 a 1966, de autoria de Jean-Claude Bernadet. Exatos quarenta anos após seu lançamento - pela editora Civilização Brasileira no ano de 1967 -, a reedição do livro é parte integrante das comemorações dos setenta anos do autor, um dos maiores críticos e pesquisadores do cinema nacional.

Ao entrar em contato hoje com o livro de Bernadet, algumas perguntas naturalmente nos ocorrem: As questões elencadas pelo autor são atuais? Quarenta anos depois, elas ainda se sustentam? Quais as contribuições que esta obra tem a dar ao cinema brasileiro presente? Para buscar uma resposta a tais indagações, levantemos tais questões.

Brasil em tempo de cinema tem um objeto de estudo muito claro e delimitado: a produção cinematográfica brasileira de 1958 a 1966. No entanto, o autor é enfático em afirmar logo no inicio que não se trata de apresentar um catálogo comentado dos filmes brasileiros produzidos no referido período, mas sim de encarar "o cinema brasileiro como um todo orgânico resultante de um trabalho coletivo". ${ }^{1}$

Para a realização de sua empreitada, Jean-Claude Bernadet utiliza uma metodologia de pesquisa própria e não muito arraigada a formalismos, que não estabelece distinções claras entre filme ficcional, filme documentário, curta-metragem, etc.; todos eles são tratados da mesma forma, como componentes do cinema nacional. Para escancarar algumas facetas da sociedade brasileira do período, sua abordagem parte das estruturas psicológicas das personagens, das composições dos espaços, ou seja, das possíveis intenções dos diretores para, então, relacioná-las com o contexto da produção. Neste procedimento, percebemos a intenção de Bernadet de mostrar como os valores políticos, morais, éticos, etc. dos diretores e, concomitantemente, da classe que eles representam, estão expressos esteticamente nas obras.

A introdução de Brasil em tempo de cinema levanta todos os apontamentos do autor que serão trabalhados no decorrer do livro, bem como sua tese principal: a produção cinematográfica brasileira é realizada pela e para a classe média urbana progressista, em busca de sua afirmação. Embora o conceito de classe média desenvolvido por Bernadet não seja tão bem elaborado - fato justificado pela escassez de estudos sobre o tema no período, bem como pelo fato de o livro ter sido produzido "no calor da hora" -, ele já indica um problema crônico da cultura no Brasil: tudo o que é produzido, em termos de cultura, é consumido pela classe média, que apropria os discursos da maneira que the provém, buscando estabelecer sua identidade. $\mathrm{O}$ autor utiliza esse conceito para demonstrar que o cinema brasileiro - mesmo o aclamado Cinema Novo - não se encontra alheio a esse problema cultural. Com todas as implicações que tal fenômeno gera, essa será a tônica de toda a obra: o cinema brasileiro de 1958 a 1966 é um cinema classe média! 
No ensaio intitulado "À procura da realidade", Jean-Claude Bernadet irá apontar um dos pontos fundamentais para a compreensão do cinema brasileiro do final da década de 1950 e início de 1960: a procura por novos enfoques. Além de superar a "pesada" herança que a chanchada e o cinema estrangeiro haviam deixado para o cinema nacional, os jovens cineastas buscam uma identidade não apenas para o cinema, mas para toda a nação. Isto é também perceptível em outras áreas, tais como o teatro (principalmente o Teatro de Arena), a música, movimentos sociais, etc.

No caso específico do cinema, essa busca vai resultar em novas experimentações estéticas. A principal indagação dos cineastas era sobre o modo de se fazer cinema. Como representar as novas perspectivas nos filmes? Segundo Bernadet, Aruanda ${ }^{2}$ oferece algumas respostas interessantes. O filme-documentário narra a história da fuga dos escravos e a instalação de um quilombo na serra do Talhado. A forma de narrativa utilizada por Linduarte Noronha aproxima o trabalho do realismo, buscando compreender intimamente as condições de vida daqueles escravos. Os recursos de produção foram péssimos, o que levou muitos críticos a taxarem Aruanda como primitivo. Bernadet critica veementemente esta posição, destacando que o "primitivismo" caracteriza uma opção do cineasta, a qual influenciaria toda a estética do Cinema Novo: uma realidade subdesenvolvida filmada de maneira subdesenvolvida. Acrescenta o autor:

No caso, a insuficiência técnica tornou-se poderoso fator dramático e dotou a fita de grande agressividade. Aruanda é a melhor prova da validade, para o Brasil, das idéias que prega Glauber Rocha: um trabalho feito fora dos monumentais estúdios (que resultam num cinema industrial e falso), nada de equipamento pesado, de rebatedores de luz, de refletores, um corpo-a-corpo com a realidade que nada venha a deformar, uma câmara na mão e uma idéia na cabeça, apenas. ${ }^{3}$

O caso de Aruanda é esclarecedor para compreendermos as facetas do cinema produzido no Brasil no período, pois demonstra a tentativa do diretor de expor o cotidiano do povo nordestino explorado e alienado utilizando como metáfora a fuga de escravos para o quilombo - metáfora também empregada em outros filmes e espetáculos, por exemplo, "Arena Conta Zumbi". O problema, de acordo com o raciocínio de Bernadet, consiste em saber para quem o filme é exposto. Para o povo explorado e alienado que se encontra nos confins do sertão nordestino, a fim de que o mesmo perceba o grau de sua alienação e se revolte contra seus patrões?

Certamente não. Primeiro, graças às dificuldades de produção e de distribuição. 0 circuito nacional era um circuito fechado - principalmente para um curta-metragem -, e ainda dominado predominantemente pelo cinema estrangeiro, sobretudo hollywoodiano. Segundo, porque o público alvo das produções não era o povo, mas sim a classe média progressista que denuncia os problemas do povo para os dirigentes do país - a qual, numa espécie de ação populista, aproxima-se das elites econômicas (e anseia se tornar parte dela) e aproxima-se também do povo explorado e alienado, buscando tirá-lo da situação em que se encontra para que o país possa progredir de maneira mais eficiente. 
Segundo Bernardet, o modo como as questões sociais do Brasil são abordadas nas películas reflete a busca de uma identidade por parte dos cineastas representantes da classe média progressista. Se fosse um cinema voltado para o povo, os filmes procurariam conduzi-lo à reflexão. Ao contrário, eles oferecem respostas e soluções prontas para seus problemas - como no caso da favela em Cinco vezes favela.

A posição dicotômica assumida pela classe média entre a elite e o povo - que reflete, em parte, a falta de uma identidade de classe sólida - aparece de maneira mais arrebatadora na construção do personagem Antônio das Mortes (Maurício do Valle), o matador de cangaceiros do filme Deus e o Diabo na Terra do Sol (Glauber Rocha, 1964). Na película de Glauber, Manuel (Geraldo Del Rey) é um vaqueiro explorado e roubado pelo patrão. A revolta com sua situação atinge níveis trágicos, a ponto de ele se rebelar matando seu patrão. Este movimento leva-o, em um primeiro momento, a associar-se ao beato Sebastião (Lídio Silva), que representa o messianismo no nordeste, uma espécie de misticismo violento e redentor; e, num segundo momento, a se aproximar do cangaceiro Corisco (Othon Bastos), que representa a violência armada. Nos dois casos, aponta Bernadet, a revolta de Manuel é uma revolta alienada, "em que o vaqueiro não afronta seus problemas, mas é desviado deles por atitudes delirantes, que canalizam sua necessidade de mudar a sociedade e sua agressividade". ${ }^{4}$

Esta posição de alienação coletiva já é abordada por Glauber Rocha em Barravento (1961), em que os pescadores buscam soluções religiosas para seus problemas reais. No caso de Deus e o Diabo na Terra do Sol - que amplia de maneira sólida os apontamentos do filme anterior - o estado de alienação de Manuel vai ser eliminado exatamente por Antonio das Mortes. É ele que extermina os fanáticos do Monte Santo, e é ele também que mata Corisco, ou seja, é Antonio que retira Manuel da perspectiva de alienação em que se encontra, permitindo que ele aja de maneira racional, buscando soluções humanas para problemas humanos. Para o diretor, esta "solução racional" só pode ser a guerra, como expressa o próprio Antonio das Mortes: "Uma grande guerra sem a cegueira de Deus e do Diabo. E, para que essa guerra venha logo, eu, que já matei Sebastião, vou matar Corisco".

Antonio, no entanto, não age de maneira espontânea como um revolucionário. Para matar cangaceiros e beatos, ele é pago pelas elites, pelos opressores de Manuel. É nessa posição completamente contraditória que, segundo o autor, se encontra a classe média progressista: sendo financiada pelas elites, ela acredita estar agindo de modo a retirar o povo do estado de alienação em que se encontra, para que possa agir racionalmente na perspectiva da revolução. Essa é a principal tese defendida pelo autor em sua clássica obra Brasil em Tempo de Cinema, razão pela qual acreditamos que Bernadet dedica seu livro a Antonio das Mortes. É ele que torna sua tese plausível.

Brasil em Tempo de Cinema contém alguns problemas conceituais e metodológicos que não comprometem em nenhum momento seu poder reflexivo. Abordando de maneira sempre instigante outras questões referentes ao cinema brasileiro, tais como embates 
com a censura (mesmo que de maneira embrionária); meios de produção e distribuição; relações do cinema brasileiro com o estrangeiro; e as relações do espectador com nossa cinematografia, sempre ressaltando os desdobramentos implicados por elas, o autor contribui de maneira efetiva para reflexões acerca do cinema brasileiro em seus diversos momentos. São essas reflexões que nos levam a avaliar a atualidade do livro quarenta anos após seu lançamento.

Para os pesquisadores que abordam o cinema nacional, principalmente os que se dedicam ao cinema das décadas de 1950 e 1960, o livro ainda representa uma importante leitura - seja pela quantidade de filmes que analisa, seja pela qualidade com que o faz, o que conduz a interessantes reflexões sobre a cinematografia referente ao período. Para os leitores que, em geral, se interessam pelo nosso cinema, a atualidade de Brasil em Tempo de Cinema pode ser problematizada levantando-se os quatro problemas fundamentais que, para o autor, o cinema brasileiro - em 1967 - havia que enfrentar. São eles: 1) levar adiante a temática da classe média; 2) enfrentar no plano policial e cultural os novos rumos tomados pela sociedade brasileira; 3 ) resolver o problema do público (sendo um cinema de classe média, não sensibiliza o povo, e sendo um cinema crítico, a classe média o rejeita); e 4) encontrar uma estabilidade econômica, esse item relacionando-se também ao anterior.

O cinema brasileiro mudou substancialmente nesses pouco mais de 40 anos que nos separam do lançamento inicial do livro de Bernadet, mas apenas o segundo problema por ele apontado foi inteiramente resolvido com o fim da ditadura militar. De 1967 até aproximadamente o fim da década de 1980 o cinema nacional pautou-se, predominantemente, pelo trabalho autoral desenvolvido por cineastas do Rio de Janeiro e São Paulo, envolvidos em conflitos de ordem ideológica e estética - os cinemanovistas cariocas rejeitavam a proposta estética e comercial dos cineastas da "boca" em São Paulo -, que eram aprofundados por discordâncias quanto à divisão dos recursos financeiros para as produções. Esse contexto foi marcado pela atuação da Embrafilme, empresa estatal responsável pelo cinema nacional, que alcançou alguns (poucos) resultados significativos de sucesso de público e arrecadação. ${ }^{5}$

Em meados da década de 1980, a empresa começou a dar sinais de desgaste, devido, por um lado, aos problemas econômicos enfrentados pelo país e, por outro, à própria falta de investimentos necessários para que o cinema nacional pudesse fazer frente à colonização "holywoodiana" e à expansão da televisão (especialmente da Rede Globo) por todo o país, que contribuiu de maneira significante para que inúmeras salas fossem fechadas. Esse processo chegou ao fim com a extinção da empresa em 1989 pelo então presidente da república Fernando Collor de Melo, marcando, para o cinema brasileiro, o fim de um ciclo. ${ }^{6}$

A década de 1990 começou com poucas perspectivas para cineastas e produtores de cinema, que viam a influência estrangeira atingir níveis inimagináveis. ${ }^{7}$ No entanto, leis de incentivo propostas pelo governo federal em 1991 (Lei Rouanet) e, principalmente, 
em 1993 (Lei do Audiovisual) prometiam investimentos na cultura através da dedução de impostos:

\begin{abstract}
A lei do Audiovisual, aprovada em julho de 1993, seguindo o mesmo principio de renúncia fiscal. Ela determina que qualquer empresa pode deduzir até $3 \%$ do imposto de renda se esse dinheiro for revertido para a produção de obras audiovisuais (artigo $1^{\circ}$ ) e incentiva distribuidoras estrangeiras a investir na produção nacional, permitindo a dedução de até $70 \%$ de seu imposto sobre a remessa de royalties para o exterior (artigo $3^{\circ}$ ). Nos dois casos, a dedução é integral e não existe a contrapartida de investimento próprio. $\mathrm{O}$ artigo $3^{\circ}$ ganhou grande importância no período da retomada, pois na prática ele estimulou a associação das grandes distribuidoras de filmes americanos no país (as majors) aos filmes nacionais. ${ }^{8}$
\end{abstract}

Com efeito, a lei do Audiovisual atraiu, gradativamente, investidores interessados no cinema nacional, que viu a produção de filmes crescer ao longo dos anos, desencadeando um processo intitulado de "retomada". Impulsionado por esses investimentos e pela associação com distribuidoras de filmes americanos - o que deu um maior padrão de distribuição, comercialização e exibição -, o cinema brasileiro expandiu-se rapidamente, conquistando indicações ao Oscar de filme estrangeiro (bastante exploradas pela mídia) e sucessos de bilheteria, como Carlota Joaquina (1995, Carla Camurati); O Quatrilho (1995, Fábio Barreto); Central do Brasil (1998, Walter Salles); e mais recentemente, Cidade de Deus (2002, Fernando Meirelles); Carandiru (2002, Hector Babenco) e Tropa de Elite (2007, José Padilha).

Após realizarmos um breve levantamento da história do cinema nacional nesses quarenta anos que nos separam de Brasil em Tempo de Cinema, voltemos às questões apontadas por Jean-Claude Bernadet. Um dos problemas consistia em encontrar estabilidade econômica, o que vimos que, embora esteja longe dos padrões internacionais, aos poucos vem acontecendo, devido a melhorias na distribuição, investimentos estrangeiros e, principalmente, ao "resgate" do público brasileiro graças à recente proximidade do cinema brasileiro com a estética holywoodiana e televisiva (leiase "padrão Globo de qualidade").

A expansão inexorável da televisão, e da Rede Globo, além de contribuir para o aumento de profissionais especializados em comunicação, permite a utilização de novos espaços de divulgação e propaganda, o que influencia de maneira objetiva o aumento do público nos cinemas. É a partir desse mote que o cinema brasileiro vai procurar resolver o problema do público, aproximando a estética cinematográfica da estética televisiva vários programas de televisão foram sucessos de público nos cinemas, por exemplo Os normais (2003, José Alvarenga Jr.).

Bernadet havia apontado como o cinema em 1967 estava alijado do público, pois, sendo um cinema classe média, o povo o rejeitava, e, sendo um cinema crítico, a classe média o rejeitava. O cinema atual resolve essa questão de modo objetivo: exclui totalmente o povo (que não é rentável), maximiza a temática da classe média, assume a identidade 
de classe e afasta-se do viés crítico (nos moldes cinemanovistas). Por exemplo, atualmente a temática que mais instiga a classe média é a violência urbana, o que se reflete no sucesso de filmes como Cidade de Deus, Carandiru e Tropa de Elite, sendo que o último é apropriado de maneira extrema como discurso pelo setor médio da sociedade. Assim, chegamos ao primeiro problema elencado por Bernadet: levar adiante a temática da classe média. O cinema brasileiro não só leva adiante, como reflete de maneira ideal o processo de afirmação da classe média brasileira frente ao processo de globalização.

Vimos como as questões propostas por Jean-Claude Bernadet para o cinema brasileiro em 1967 foram deglutidas, desvirtuando-se essencialmente da perspectiva do autor. Soluções para os problemas elencados por ele foram propostas ao longo da história do cinema nacional, mas a própria maneira como foram propostas reflete sua atualidade.

\footnotetext{
*André Luis Bertelli Duarte é graduando em história pela UFU.

${ }^{1}$ BERNADET, J.-C. Brasil em tempo de cinema: Ensaio sobre o cinema brasileiro de 1958 a 1966. São Paulo: Companhia das Letras, 2007, p. 21.

2 Filme de cerca de vinte minutos produzido por Linduarte Noronha com a colaboração de instituições de João Pessoa, Recife e Rio de Janeiro (Instituto Joaquim Nabuco, Secretaria da Educação da Prefeitura de João Pessoa, Associação dos Críticos Cinematográficos da Paraíba e Instituto Nacional de Cinema Educativo), e apresentado na Primeira Convenção da Crítica Cinematográfica provida pela Cinemateca Brasileira no ano de 1960.
}

${ }^{3}$ BERNADET, J.-C. Op. cit., p. 38.

${ }^{4}$ BERNADET, J.-C. Op. cit., p. 94.

${ }^{5}$ Dentre as produções de destaque, podemos salientar "Dona Flor e Seus Dois Maridos" (1976) de Bruno Barreto que foi visto por mais de 11 milhões espectadores.

${ }^{6}$ RAMOS, A. F. "Apontamentos em torno do cinema brasileiro da década de 1990". In: Nuevo $\begin{array}{llllll}\text { Mundo Mundos Nuevos, n. } & 7 & \text { (2007). } & \text { Disponível }\end{array}$ "http://nuevomundo.revues.org/document3378.html". Acesso em 30/05/2007.

7 Entre 1992 e 1994, por exemplo, apenas 13 longa-metragens chegaram ao circuito exibidor, pelas mãos da Riofilme. A número de espectadores, em cada ano, não chegou a $1 \%$ dos ingressos vendidos no país. Dados da publicação Cinema brasileiro: Um balanço dos cinco anos da retomada do cinema bacional, lançada pelo Ministério da Cultura em 1999. Apud: BUTCHER, P. Cinema Brasileiro Hoje. São Paulo: Publifolha, 2005, p. 21.

${ }^{8}$ BUTCHER, P. Op. cit., p. 19. 